\title{
1. The judge: a new actor in the political landscape
}

\subsection{ANALYZING THE ADMINISTRATION OF JUSTICE}

As is the case for other research fields, both the judicial system and the actors performing its numerous functions can be observed from different perspectives and, to a certain extent, these may complement one another. Although legal scholars were the first to engage in this field - practically colonizing it for some time - the social scientists who came later developed an increasingly rich toolbox that now includes a variety of methods, theories and concepts progressively devised to approach the multifaceted world of justice. Our attention will focus more closely, though not exclusively, on the latter framework.

In the European context, academic lawyers have traditionally cultivated the study of courts, judicial procedures and jurisprudence, mostly favoring a legal dimension. The formal rules that establish how the system should operate and how the judiciary should act are doubtless fundamental components of the administration of justice insofar as they provide valuable information that scholars cannot neglect whatever their perspective. Yet we know that implementing rules is neither a simple nor an obvious process. Laws do not always generate the expected outcomes owing to a host of factors, ranging from the nature of the issues to be addressed to the complexity of bureaucratic machineries. Such factors may also produce distorting or undesirable effects in implementation and laws may even remain totally or partially unenforced (Howlett and Ramesh 1995).

To describe how judicial institutions work in practice, it is thus necessary to look beyond the normative dimension. Appropriate instruments are, therefore, required to investigate both sides of these institutions: how actual behavior develops, and interactions within this environment. This approach enables us to present an image of justice not solely confined to formal data.

With this aim, contributions from other scientific fields have multiplied since the middle of the past century, first in the United States and later in Europe. All of them fall within the extended family of social sciences. Although they differ greatly, these studies generally tend to give priority to the operational 
dimension of justice. In other words, the need for an empirical foundation leads them to investigate the functioning of the system and its actors' behavior to uncover factors that can explain what has been observed. Contributions of this type come from sociologists and economists, who in recent years have taken an increasing interest in this area, and above all from political scientists. The growing number of political analyses, both comparative and focused on individual systems, also consider countries that were overlooked or even ignored until recently, reflecting on legal traditions and political regimes that may be examined in the context of their historical evolution to highlight the role of justice at critical junctures, especially in democratic transitions.

Comparison is one of the methods that empirically based research applies to address issues concerning institutions, groups and rules observed in their mutual interactions and in relation to the specific environments in which they emerge and take form (Morlino 1991, 13). Broadly speaking, comparative analyses move from a research problem to generate one or more hypotheses about plausible answers and explanations. To ascertain their validity, these analyses rely on comparison of concrete cases - a set of countries of variable size - based on properly structured variables selected according to their relevance vis-à-vis the hypotheses that have been envisaged. We will follow the same path by drawing predominantly upon the scholarly literature in the field of social sciences that has addressed the topics of interest here: the system's main actors, especially judges and public prosecutors, and the guarantees they enjoy as well as the organizational settings in which they operate; the cultural and political understandings of these roles, whose relevance is determined by the influence that such conceptions normally exert on actual behaviors; the main structures and devices serving the system's various functions and their decision-making processes; and the multiple and complex interactions that take place between justice and its social and political environment.

These and other variables that will be considered later are intended to shed light on the core problem of the present analysis, namely the increasing political significance that courts have achieved in many contemporary societies. More specifically, the aim is to clarify the reasons behind this phenomenon - conventionally labelled as the "judicialization of politics" - and the factors that may help in understanding why and how it emerges and develops, and why some countries appear better equipped to tackle this evolution. The concrete cases that will be examined in more detail are all consolidated democracies: England, France, Germany, Italy, Portugal, Spain and the United States. However, especially in Chapter 8, other cases will be considered to illustrate specific trends or explanations and to consider the role of justice in non-democratic and transitional regimes as well as in countries where the liberal legacy appears in question. 
Although mature democracies are widely discussed in scientific literature, we also selected the cases we analyzed to represent the two great Western legal traditions: civil law, which originated in continental Europe but later took root in Latin America too, and common law, which took shape in England around the twelfth century and now covers former British colonies, including the United States, and other countries that have been exposed to English or American influence. Despite their subsequent and recent developments, these two traditions still exhibit significant variations in the institutional arrangements of justice and can, therefore, still aid in explaining several of the topics we discuss.

\subsection{THE JUDICIALIZATION OF POLITICS}

Over the last decades, social scientists studying the intersection between courts and politics have been paying closer attention to a phenomenon already apparent in the 1980s and subsequently reported in many democracies, both mature and emerging: the judicialization of politics. Relevant decisions that once fell almost exclusively within the realm of parliaments and governments have been increasingly taken over by courts and tribunals that are thus in the position to affect the public space - that is, politics as well as policies - to an extent much greater than in the past. Consequently, the role of judges today appears de facto different from the one they played (and were expected to play) in the past. The typical function of courts - to resolve controversies on the meaning of the formal rules to be enforced in concrete cases - has been extended to include a variety of conflicts that concern the building blocks of collective action: legislation, whether it is compatible or not with higher norms, be they domestic and/or supranational; the effective compliance of public administration with legal dispositions regulating its action, also in order to protect individuals from improper practices; the division of powers between the branches of the state, and therefore the relationships between the legislature, the executive and the judiciary itself; the jurisdiction of subnational political entities and their autonomy from central governments; the rights granted to ethnic, linguistic or religious groups present in the national territory; and even regime changes along with the treatment of those previously in power (Hirschl 2008).

As we will see, especially in Chapter 7 , this is a preliminary and non-exhaustive list, but the central point of our argument should be clear: issues related to the core constituents of polities can be, and often are, brought before courts.

Undeniably this development is mainly connected to the spread of constitutional review, thanks to the processes of democratization that have taken place over the last century. Yet looking back, this phenomenon does not appear so recent. As early as the first half of the nineteenth century Alexis de Tocqueville 
(1835-1840) had discerned a similar pattern in the United States, arguing that there was hardly any political question in the US that did not turn into a judicial question sooner or later. Even earlier, the fear of "government by judges" in the French Ancien Régime could be considered an antecedent ${ }^{1}$ of this evolution as well as the indicator that, under certain conditions, this phenomenon may also occur in non-democratic regimes. However, the rise of the judiciary has often been supported by the emergence of liberal democracies owing to the proliferation of constitutional review and the related broadening of courts' decision-making rights.

In fact, the judicialization of politics has been defined as "the expansion of the province of the courts or the judges at the expense of the politicians, and/ or the administrators, that is, the transfer of decision-making rights from the legislature, the cabinet, or the civil service to the courts" (Vallinder 1995, 13). ${ }^{2}$ Years later, this definition is still helpful as it grasps the path followed by many political systems while stressing its most relevant outcome: the political salience that courts often display. Yet it is necessary to better specify the meaning of this definition and to add several supplementary elements.

First, the expansion of justice may well occur at the expense of the executive and the legislature; indeed, there is no lack of examples. However, it does not always and inevitably determine a corresponding retreat of parliaments and cabinets. The concept of "transfer of decision-making rights" - in essence, the relocation of power - cannot alone account for the complex institutional interactions and dynamics in which judges are called upon to decide. The reason for this is that the increasingly significant role of courts in the political process does not necessarily entail a zero-sum game. In other words, gains do not always correspond to losses of power between the participants. Indeed, some authors suggest that "Courts and politicians coordinate in a myriad of ways and affording courts more power can simultaneously strengthen a political regime" (Kapiszewski, Silverstein and Kagan 2013, 36). Judges operate in dense

1 We refer here to the case of the French parlements, the appellate courts of the old regime, which appropriated the power to review the rules issued by the king based on the unspecified higher principles of monarchy. This experience, that the Revolution swept away, produced an enduring legacy in the French constitutional arrangements and on other European systems since it determined the continued refusal to adopt any form of constitutional review of legislation, especially if entrusted to the judiciary (Rebuffa 1993).

2 Vallinder $(1995,13)$ points also to a second development, namely the "spread of judicial decision-making methods outside the judicial province proper", that we do not consider here. Wherever this phenomenon occurs, it is a likely consequence of the first (Hirschl 2008). Moreover, the diffusion of independent regulatory agencies, which exhibit court-like decision-making methods and features, can erode the scope of courts, especially if such bodies effectively perform the functions entrusted to them. 
spaces - populated by public institutions, political parties, interest groups, social movements - and under certain circumstances they may take the environment into account before making their decisions (Devins and Fisher 2015). Of course, one could argue that there is no reason for courts to be concerned about potential reactions to their decisions, especially supreme and constitutional courts, which generally issue final, and therefore binding, judgements and formally have the last word. In fact, parliaments and governments have both formal and informal instruments that enable them to react to unwelcome judicial decisions; something they seek to do with some frequency. However, parliaments and governments can implement measures to achieve such goals, that is, changes in the content of judges' decisions, in the presence of certain social and political conditions. Furthermore, we should note that court rulings do not always achieve their intended effects. To have their decisions enforced, courts often need the cooperation of other actors such as public agencies, other judicial bodies or the citizenship at large. Yet cooperation, even when formally prescribed, should not be taken for granted. From this perspective, courts are not final decision-makers. Instead, they concur in shaping collective choices through a sort of "dialogue" with multiple actors (Stone Sweet 2004). Where the political relevance of justice is on the rise, this dialogue may easily generate short- or long-term tensions, but it may also enable forms of overt or unspoken collaboration (Whittington 2005). Ultimately the empowerment of courts, although indisputable, takes place in a dense context where actions and inactions, decisions and non-decisions, tactics and strategies by all participants are in order (McNollgast 2006). To grasp these dynamics and their outcomes, it is necessary to consider not only the social and political conditions featured by individual systems but also how judges interpret their own role. The propensity of courts to enact the powers with which they have been entrusted, either broadening or reducing their reach to engage in activism or in self-restraint, is of particular importance.

Second, and for the reasons sketched above, the tendency to endow courts with relevant powers is visible and consolidated in many systems - as will be seen in Chapters 3 and 4 - but this is not irreversible. Ultimately those powers depend on choices made in legislative venues, although there are cases in which the courts themselves have widened their own jurisdiction through "expansive" constructions of the pertinent legal instruments. Where judges exercise their powers vigorously, legislatures may seek to subvert this tendency or at least to slow it down (and may possibly succeed). Attempts like this can be detected in consolidated democracies. ${ }^{3}$ However, younger democ-

3 An attempt to move in this direction was provided by the UK. In 2015, the Conservative Party, at that time led by David Cameron, announced its plan to revise the 
racies are more vulnerable to such events, especially in cases where the rule of law is not yet engrained in the culture of the polity and its elites, or where the courts are not sufficiently supported by the political establishment, the civil society and the other legal professions. ${ }^{4}$

Third, the judicialization of politics is fed by another indispensable ingredient, previously unmentioned yet crucial: the independence of judges. We will discuss this concept in Chapter 2, while the concrete institutional setting in various countries will be examined in Chapter 5. The possibility for courts to affect the public space clearly depends on the magnitude of conflicts they are asked to settle, but it also relies on the courts' autonomy from the preferences of government institutions. Failing this ingredient, courts are configured to be the transmission belt for powers located elsewhere, and this is historically the stuff of totalitarianisms (Kirchheimer 1961). Nonetheless, even the emergence of liberal democracies does not necessarily result in increased judicial independence. An enduring tradition in continental Europe has long reined in the rise of the third branch of government by depicting the judge as the passive executor of the legislative will and by organizing the judiciary as a mere bureaucratic machine placed in a subordinate position. In more analytical terms, when referring to the judicialization of politics a basic distinction should be made between the broadening of court jurisdiction and the strengthening of the guarantees of judicial independence. The first element without the second may result in a politically relevant judiciary, which, however, remains hetero-directed. Likewise, courts sufficiently protected but having limited competence can hardly nurture judicialization. ${ }^{5}$ Ceteris paribus, the power of judges is, therefore, more likely to unfold in systems where courts are endowed with relevant functions, the judiciary is properly protected, and - last but not least - it devises more activist understandings of its own role.

Human Rights Acts 1998, which was held responsible for expanding the role of courts at the expense of the Westminster Parliament (Protecting the Human Rights Act in the UK - The Conservative Party, www.conservatives.com, last accessed on 11 October 2019). We will come back to this reform in Chapter 3.

4 As we will see in Chapter 8, a pertinent example is provided by the recent reform of the Hungarian Constitution, introduced by Victor Orban in 2013, but also made possible by the general political evolution of the country. The reform has seriously reduced both the scope of the Constitutional court, once amongst the most activist in Central-Eastern Europe, and some fundamental rights of citizens subject to judicial proceedings.

5 As we will see in Chapters 3 and 8, a strategy often followed by authoritarian rulers in order to contain court power consists of narrowing their jurisdiction, while preserving guarantees of judges' independence to some extent. In contrast, totalitarian regimes tend to permeate the judiciary and turn it into a subservient instrument for perpetuating their power. 
Finally, the expansion of the judiciary, although regarded as one of the major developments in contemporary democracies (Hirschl 2006), does not occur everywhere and to the same degree. As noted above, the path followed in individual countries depends on a vast array of factors that can either foster or discourage judicialization and take on different forms which, moreover, are not immutable over time. While the actual blend of such factors in the domestic scene is always of paramount importance, external influences, both supranational and international, can hardly be overlooked. In the external environment, some long-term trends which concur in the rise of the judiciary, have been - and still are - at work, thanks also to the circulation of ideas engendering attractive and influential paradigms.

\subsection{THE JUDICIARY, ON THE RISE: THE LONG-TERM FACTORS}

Since its inception, the United States have recognized the judiciary as the third and coequal branch of government, on a par with the executive and the legislature. It is hence unsurprising that, as Tocqueville remarked, justice acquired a significant political role in the United States long before Europe. The main features that clarify both the strength of the US judiciary and some of the counterweights to its power are: a democratic regime legitimized by popular elections and endowed with a written constitution conceived to rein in political power which is divided between the branches of government through a system of checks and balances; a constitutional catalogue of justiciable rights that may be invoked in court, thus limiting the will of legislative majorities; a federal system that, in turn, divides the political power and relies on judges to resolve conflicts arising along the "center-periphery" axis. Aside from federalism, to which we will return later, the rise of justice in many countries has been supported by the gradual spread of these principles and their related institutional frameworks even though variations at national levels are countless and often substantial. This process developed first in Europe, where other long-term trends equally facilitated this evolution, then later spread to other regions.

\subsubsection{Democratization}

Apart from country-specific features, it is thus possible to spot some major social and political developments that at different times and in various ways have fostered a twofold pattern: the tendency toward broadening the jurisdiction, namely, the cases and controversies that can be brought before a judge, and the increasing emphasis on the independence of the judicial function.

The process of democratization has provided the political impetus for progressing in these directions. For our purposes, all democracies practice some 
form of division of powers, while not necessarily establishing the judiciary as a "real third power", and commit themselves to protecting the independence of courts. The democratic transitions that took place in the twentieth century thus enhanced the gradual dissemination of these principles: this was so at the core of the Old Continent following the fall of the Fascist and Nazi regimes after the Second World War. The 1970s then witnessed the emergence of democracy on the Iberian Peninsula and in Greece. About two decades later, this process gained new momentum in Central-Eastern Europe owing to the rending of the Iron Curtain, in Latin America, thanks to the demise of the authoritarian dictatorships and later reached South-East Asia and post-apartheid South Africa.

Of course, this does not imply that democracy has succeeded on a global scale. In several geo-political regions, ongoing factors of fragility and actual risks of reverting to authoritarianism persist, not to mention democratic failures and countries that still appear impervious to this evolution. More important, however, is that this process has accredited democracy as the proper recipe of good governance, turning it into an international benchmark for checking the health of political systems, the degree of freedom they ensure to their citizens, the quality of the administration of justice and, not least, their economic performance. ${ }^{6}$

Above all, and most importantly, democratic transitions are often coupled with two elements: written constitutions and courts that are called upon to act as their guardians. In other words, regime transitions have often resulted in the emergence of constitutional democracies.

\subsubsection{Constitutionalism}

Hence, the diffusion of democracies has often been associated with a second major development. The term "neo-constitutionalism" (Stone Sweet 2000; Hirschl 2006) has been coined to define this development and to distinguish it from both the ancient Anglo-Saxon constitutional tradition, which has its roots in the medieval age, and the constitutional regimes of the nineteenth century (McIlwain 1940). This new constitutionalism can be understood as a set of principles and institutional devices devoted to moderating political power, containing the potential excesses of majority rule, and therefore mitigating democracy itself. Its main purpose is to protect freedoms, primarily individual freedoms. In fact, the first European countries that moved in this direction

6 The full range of these intertwined elements may press non-democratic regimes to promote some liberal reforms as well as some guarantees of judicial independence to gain credits on the international scene, encourage investments from abroad and stimulate economic growth (Hayo and Voigt 2007). 
after the Second World War, namely Germany and Italy, retained a memory of freedom-destroying regimes that had become established in accordance with formal constitutional requirements.

The reaction to the past that marks these and other democratic transitions in Europe has determined relevant consequences. First, the assumption that laws enjoy per se a full-fledged legitimacy has been swept away (Ferrarese 2010, 128), along with the indisputable primacy of legislative majorities. ${ }^{7}$ For this reason, higher rules have been adopted - the so-called "rigid constitutions" which can be amended only by means of special procedures requiring qualified majorities. Second, most countries have also chosen to incorporate a judicial check on the effective compliance to such fundamental rules that gives courts a de facto veto power over legislative deliberations. Essentially, the new constitutionalism has reinstated the values of "limited government" - in this case, of democratic regimes that bind themselves to protect freedoms - also through courts of justice that are not dependent on the government.

More broadly, these developments have generated a long-term process which has led to an emphasis on non-majoritarian institutions - those which are detached from the political arenas operating under majority rule - first and foremost, the judiciary. The spread of constitutional democracies has thus gradually strengthened the independence of judges and to a certain extent also that of public prosecutors - namely, those in charge of promoting criminal proceedings and who play a distinct function in the judicial system. Moreover, this spread has entailed significant changes in how judges and prosecutors understand their own role, as we will see in more detail in Chapters 5 and 6.

In Europe, the renaissance of constitutionalism has not only taken place in national contexts. Its guiding principles and its institutional devices have been rapidly transplanted both at the supranational level, in the organization that would later become the European Union (EU), and at the international level, through the European Convention on Human Rights (EHCR). Since the 1950s, these new entities have introduced two judicial guardians, the Court of Justice of the European Union in Luxembourg and the European Court of Human Rights in Strasbourg. Both have entered areas that were to develop while becoming more complicated. The twofold process of democratization and of European enlargement has brought an increasing number of national jurisdictions in these (partly overlapping) regions. In turn, these courts have engaged in an ongoing dialogue both with the European courts, through their decisions, and with the so-called "judicial networks", namely, collegial bodies

As Grimm (1999, 197-198) has suggested, democracies exclusively based on the majoritarian principle cannot "prevent the majority from abolishing the majority rule by a majority vote". 
which represent the various structures of the judicial system (Dallara and Piana 2015). This path has proved to be anything but straightforward since its stakes were, and still are, the sovereignty of the member states and the autonomy of their respective highest jurisdictions, that is, national supreme and constitutional courts (Sadursky 2008). Nevertheless, its outcome resembles that just depicted. As regards the EU, a multi-level system has emerged in which the European rules now stand above domestic legislation and constitutions. The "watchdogs" overseeing the respect of these rules are the judges, including national ones. In this domain, a "constitutionalization" of member states" commitments has occurred, which has found its major architect in the Luxembourg court (Stone Sweet 2004; Horsley 2013). The cooperative relationship it has established with national judges is considered an integral part of this regional development and evidence of a wider judicial globalization (Slaughter 2003).

Not surprisingly, a paradigm took root over time in the European context; it comprises some essential ideas that were subsequently converted into rules, recommendations, reports and judicial decisions. The core of this paradigm lies in the rule of law, the constitutional state. Besides the courts themselves, influential actors on the national and international scene such as the World Bank, have actively promoted the rule of law and the institutions on which it rests (Piana 2010). One of its pillars is the independence of judges who bear the responsibility to enforce legally binding norms even against the majority's wishes to ensure that majorities comply with the commitments they have made in laws, treaties and conventions. We will see that, owing to these core ideas and the active engagement of judicial networks, the independence of courts has grown substantially.

\subsubsection{Rights Protection}

The expansion of justice has also been fostered by the newfound awareness of rights prompted by the experience of the twentieth-century dictatorships which led to the Second World War (Cappelletti 1989). Since the 1950s, many European parliamentary systems have moved toward the judicialization of politics thanks to a refreshed view of democracy as a primarily rights-oriented regime (Strøm, Müller and Bergman 2003, 651 ff.). Seen as building areas of freedom, and therefore as limits on legislative power, rights are now expressly envisaged in most contemporary constitutions, Bills of Rights (as in Canada), charters regulating regional treaties (as in the EU), and international conventions such as the ECHR and the Inter-American Convention on Human Rights. All these are binding normative sources, the respect of which rests in part on the possibility to appeal to as many courts.

Firmly established in the legal and political cultures of constitutional states, rights have steadily increased. Alongside the classical rights - civil, political 
and social (Marshall 1963) - other types of rights have emerged that have been supported by cultural, economic, scientific and environmental changes as well as by the rapid growth of the new media. ${ }^{8}$ The driving forces behind this "revolution" (Epp 1998) are numerous but some of them have played, and are still playing, a prominent role. Firstly, one must consider the pressure exerted on public institutions by individual and collective claims searching for answers or recognition. The legal professions - academic and practicing lawyers - also contribute to this development insofar as they can supply claims with the ideas and the technical skills required to bring actions. Obviously, the courts themselves fulfill a fundamental function in this respect. The human rights discourse is primarily shaped in these venues that may cooperate in its construction and sometimes even compete to take the lead in this dialogue (Lasser 2013). Finally, it has now become standard to mention the often-mounting demand for justice, which is clearly facilitated by the opportunities for litigants provided by judicial proceedings, but which is also contingent upon the capability and willingness to respond by other institutions. Generally, however, poor or modest systemic performances are likely to encourage disappointed claims to address the judicial authorities.

Owing to these developments, legal rules and judicial proceedings are increasingly used as leverages when seeking to advance interests that are political in nature - at least, because they call into question the co-existence in the polis, and therefore the allocation of values therein (Easton 1965) - but worded in the language of law and rights. This way of using the judicial process, which has traditionally been a feature of the United States (Kagan 2001), is now a common trait not only of consolidated democracies but also of countries where groups or social movements seek to promote a liberal agenda by resorting to courts (Karpik and Halliday 2011).

\subsubsection{The Public Space}

The use of law in the manner just outlined has found a favorable environment in the contemporary state, which has increasingly relied on legal instruments to run government and, to a lesser extent, to regulate international relations. Since the first half of the twentieth century, Keynesian policies aimed at stimulating public intervention in the economy and welfare policies designed to support the implementation of social rights have brought about a quantitative growth

8 Giovanni Sartori (2013) argues that rights have changed their content because of this process. While they initially pursed protection from the government, they later turned into claims - to education, health, employment, etc. - to which governments commit to comply. 
of both the legal rules and administrative agencies created to enforce them. Justice has not escaped this expansion. Obviously in a constitutional state, where a legal rule exists there is also a judge who is likely to be asked to interpret and apply it. This implies that public bureaucracies are subject to judicial review that will check their compliance with the relevant legal dispositions upon the request of those having an interest at stake.

The expansion of government action, which has extended well beyond the traditional boundaries of military defense and public order policies, has thus determined an almost parallel expansion of the courts' jurisdiction (Cappelletti 1984, 31). Perhaps counterintuitively, subsequent neoliberal policies - privatizations of utilities that were once in public ownership and even the retreat of welfare policies - do not appear to have substantially reduced the scope of lawmaking that today takes the form of widespread regulation of individual and collective behaviors (La Spina and Majone 2000). Indeed, Lawrence Friedman $(1985,22)$ noticed years ago that in "contemporary law, as compared to a century ago, no area of life is completely beyond the potential reach of law $[\ldots]$ There are fewer and fewer 'zones of immunity' from law". Moreover, it is worth noting that legislative regulation is often prompted by a pervasive demand for security that, though changing across time, most frequently originates from the society or organized segments thereof. ${ }^{9}$

Government intervention, although remarkably rearranged in some of its properties, has thus continued to foster conflicting claims that, for this very reason, are bound to be at least partially frustrated. Recently, several European countries have also experienced a declining trust in their classic political institutions - parliaments, executives, bureaucracies, political parties - which has contributed to channeling dissatisfied claims toward courts. Hence, multiple and intertwined factors combine to propel the demand for justice: the human rights discourse, the national and supranational constitutionalism, the reshaping of welfare under the pressure of financial and economic crises, the difficulties that political institutions face in responding to internal and external challenges and the global learning process about the use of law. Such factors are decreasing the differences among legal cultures (Friedman 1994) and turn the judicial process into a device for advancing individual and collective claims. This device, it must be added, is characterized by a structural advantage compared with the traditional policy circuits: unlike other institutional

9 Friedman (1985, 46 ff.) also argued that nineteenth-century society was intimate with death and used to uncertainty in every aspect of daily life. The demand for public intervention to cope with risk - the forms of which have undergone dramatic changes over time - has been a powerful driver of the proliferation of rules, ranging from welfare policies to the current anti-terrorism measures and the restrictions these often entail on individual rights (Volcansek and Stack 2011). 
actors, judges are almost invariably required to give an answer once a case has come before them.

\subsection{COURTS AND THE POLITICAL SYSTEM}

The chances for judges to have a say in collective issues are also related to the environment in which courts are embedded and with which they de facto interact: national, and to some extent also supranational, political systems. While the long-term trends considered so far can clarify some major developments featured by many contemporary polities, we must perforce consider each political system to shed light on the actual relevance of courts. This means that the driving forces behind judicialization or its absence are mainly country specific. Factors operate at this level that can account for this phenomenon, its different degrees of intensity, the various forms it may take and their possible connections, as well as its possible latency.

At the most general level, courts find an environment more conducive to the expansion of their influence in systems that distribute, and therefore fragment power much more than in systems that, in contrast, tend to centralize power. Hence, the institutional arrangements of political systems and their overall internal dynamics matter. Both of these elements, along with their variability, enable us to better appreciate the role that the courts and the judiciary effectively play in individual systems.

As noted above, democracies always engage in some form of division of powers, a fact that opens them to the expansion of the judicial system to a greater extent than other regimes. This does not preclude, however, that significant variations exist both in the design and in the relationships established between the branches of government. To outline such differences, we may rely on the renowned distinction between majoritarian and consensual - or better proportional - democracies (Lijphart 2012). Where the political power is more concentrated, ruling majorities have more instruments at their disposal for reining in judicialization or at least for reacting to unwelcome judicial decisions, provided that such majorities are sufficiently cohesive and stable. As we will see in more detail in Chapter 7, a vast array of strategies are available to rulers willing to do this, from not enforcing judicial decisions and thus reneging on the collaboration of institutions that should implement them, to legislative reforms devised to curtail either judicial independence and/or judicial scope. Moreover, it may be superfluous to apply such measures. The mere willingness to commit to these or similar courses of action, if announced and substantially threatened by a purposeful majority, can send a clear message to the courts (Vanberg 2001; Clark 2011). Essentially, the cohesiveness of political power is a necessary, albeit insufficient, condition to limit the judiciary's expansion and assertiveness. On the one hand, it enables extant majorities to 
adopt "countermeasures", which can prove to be of variable effectiveness, aimed at containing this phenomenon; on the other, it lends credibility to the threat of legislative interventions pursuing this aim.

For the same reasons, institutional arrangements that fragment political power face serious obstacles in curbing judicialization. In fact, they inherently tend to enhance it (Ferejohn 2002). Where political decisions must be negotiated with multiple actors ${ }^{10}$ - some of whom are surely endowed with a power of veto - measures to withstand the collective impact of justice are more difficult to achieve; moreover, the threat to resort to such measures lacks credibility. In fact, a tendency toward consensual arrangements - that is, toward power sharing and negotiated lawmaking - is likely to result in shifts of power in favor of other institutions, including the judiciary (Ferrarese 2002). Furthermore, in these contexts the traditional venues and decision-making processes are more likely to exhibit lower levels of performance; this fact reduces their governments' ability to respond, or at least to react, quickly to social demands and it is, therefore, more probable that disgruntled claims and frustrated expectations move in other directions and exploit the opportunities offered by the judicial process.

Summing up, the incidence of justice is related to the dislocation of political power. Hence, the importance of institutional architectures and especially of those that fragment power and are likely to amplify the role of courts. As was noted in relation to the United States, federal structures also push in this direction. Such arrangements divide power along the vertical "center-periphery" axis, ${ }^{11}$ rest on different or even opposing political majorities, and usually entrust the task of resolving conflicts between the "center" and the "periphery", as well as among the "peripheries", to supreme or constitutional courts

The fragmentation of power may also result from the intersection between the institutional design and the actual political dynamics. Thus, a clear division of powers along the horizontal axis - that is, between the executive and the legislature - may make their de-alignment likely. One might consider the frequency of "divided government" in the United States, when the president faces one or both houses of Congress under the control of the opposition; or in the case of France, a dual executive system, where the directly elected president of the Republic can cohabit with a majority of a different political hue. Electoral legislation and the way in which politicians design and use these crucial laws is also important. These elements, namely, rules and strategies,

10 We refer here to consensual democracies, which rest on negotiations between several political actors (Vassallo 2016).

11 Here we use these terms to point out that similar features are also found in systems that recognize wide territorial autonomies, such as in Spain and Italy, and confer legislative prerogatives to subnational entities. 
affect the number of political parties, if and how they compete, the format of government coalitions and the probability of having a majority controlling both houses of parliament. Laws regulating competition in the electoral market and the choice of political agents can thus push the political system toward either a proportional, namely, power-fragmenting, setting, or toward a more majoritarian arrangement.

Finally, as we will discuss more deeply in Chapter 7, institutional arrangements that fragment power can result from democratic transitions, where no political forces are able to catalyze and control the process. Constitutional arenas characterized by several competing actors, low levels of mutual trust, uncertainty about future election results and diffuse risk-aversion are more likely to strengthen judicial institutions. An independent judiciary and courts endowed with robust powers may be perceived as insurance devices that can ensure compliance with rules, and therefore also be capable of safeguarding the losers in the electoral arena. In other words, powerful courts may be viewed as an anti-majoritarian insurance, enabling all actors to take precautions against the risk of electoral defeats and mitigate the costs thereof (Ginsburg 2003).

In conclusion, while the engines of judicialization are numerous and active in many polities, the specific reasons behind this evolution, its various gradations and shapes are to be detected in individual contexts. It is necessary to consider the social, political, institutional, and cultural features of each setting by observing not only judicial prerogatives and independence but also factors that foster the judiciary's willingness and capacity to use these resources and to play a de facto political role (Woods and Hilbink 2009, 746). 